Gómez, R. L., Ali, A., \& Casillas, W. (2014). Mentorship and the professional development of culturally responsive evaluators in the American Evaluation Association's Graduate Education Diversity Internship (GEDI) program. In P. M. Collins \& R. Hopson (Eds.), Building a new generation of culturally responsive evaluators through AEA's Graduate Education Diversity Internship program. New Directions for Evaluation, 143, 49-66.

\title{
Mentorship and the Professional Development of Culturally Responsive Evaluators in the American Evaluation Association's Graduate Education Diversity Internship (GEDI) Program
}

Ricardo L. Gómez, Asma Ali, Wanda Casillas

\begin{abstract}
In this study, we used $Q$ methodology to investigate perspectives on mentorship among alumni of the Graduate Education Diversity Internship (GEDI) program. We asked participants to think retrospectively and give their opinion on the most important characteristics a GEDI mentor should have, based on what they would have liked or needed when they participated in the GEDI program. Three different perspectives on mentoring emerged from participants. They show that mentoring is not unidimensional; that perceptions and expectations of mentoring are defined to a great extent by the professional needs, background, and expectation of the participants. We suggest that the program takes those needs and expectations into consideration and use them as criteria for selecting mentors. (C) Wiley Periodicals, Inc., and the American Evaluation Association.
\end{abstract}

\section{Program}

The American Evaluation Association Graduate Education Diversity Internship (GEDI) program is currently in its 10th cycle and has 62 alumni and

The authors of this chapter participated in Legacy, the fifth cohort of the AEA GEDI program. 
alumnae. Mentorship is a core feature of the GEDI program, which is advanced and utilized as a distinctively interpersonal form of learning. During the GEDI program, formal and informal mentorship of the interns is combined with professional development workshops, participation in conferences, and hands-on evaluation experience through practical evaluation projects to introduce students to the evaluation profession. After participants complete the internship, formal mentorship relationships developed during the program are encouraged to continue as a part of the alumni experience. Though all components of the program work in concert, mentorship and networking are essential to the GEDI program experience.

In this study, we sought to understand perspectives on mentorship among alumni of the GEDI program. Particularly, the current study focuses on what participants think should be the most important characteristics of a GEDI mentor.

This study is based on the premise that mentoring is a powerful personal and professional development tool—one that is multidimensional and can serve different purposes. Thus, we expect to contribute to the evolution of the GEDI program by tapping into the experience of former participants and channeling their opinions into an explanation of what sort of mentorship would have been most relevant to them based on their experience, career goals, and professional aspirations.

The authors used Q methodology (Brown, 1980; Stephenson, 1953) as the main tool for inquiry. $\mathrm{Q}$ is an established methodology used to investigate people's subjectivity-i.e., opinions, beliefs, or attitudes about an issue. Participants were asked to sort a set of statements that characterize mentorship relationships. Then, participants' rankings were analyzed using correlation and by-person factor analysis (Stephenson, 1953), resulting in three distinct factors interpreted to better understand the mentorship experiences of the GEDI interns. The factors are discussed with implications for the continued mentorship of future GEDI generations.

\section{Background}

Existing literature cites numerous benefits of mentorship to early career participants-known as protégés-in these relationships (Chao, Walz, \& Gardner, 1992; Scandura, 1992; Whitely, Dougherty, \& Dreher, 1992). Professional articles on the role of mentorship on professional development abound across several academic literatures, including higher education, health professions, and teaching. These articles often include conceptual models of the mentorship program, including the structure of formal mentorship programs, or suggest requirements for informal mentorship programs related to specific careers or interests. More recent studies point to positive outcomes for early career mentees compared to their peers who do not participate in mentoring relationships. 


\section{Definitions of Mentorship}

The traditional definition of mentorship describes a "relationship between a younger adult and an older, more experienced adult [who] helps the younger individual learn to navigate the adult world and the world of work" (Kram, 1985, p. 2). The study of mentoring relationships is often traced to the seminal work by Levinson, Darrow, Klein, Levinson, and McKee (1978) on the career development of adult men. In their work, Levinson and colleagues describe the relationship that develops with a mentor as one of the most important experiences of early career and young adulthood.

Mentors reportedly are not only a source of learning for protégés, but they also play a key role in the development of protégés' self-esteem and work identity (Dalton, Thompson, \& Price, 1977; Kanter, 1977; Shapiro, Haseltine, \& Rowe, 1978). These studies point to positive career outcomes for the protégés who are engaged in mentor relationships. Later work by Kram (1985) points to two tracks of mentorship outcomes associated with this relationship: (a) formal knowledge and skill building, and (b) psychosocial development. In recent years, emerging literatures have differentiated between two distinct types of psychosocial career outcomes associated with mentorship. The primary outcomes include easily measurable components such as salary and promotions, while secondary career outcomes include career satisfaction and professional networking opportunities. A wide variety of mentorship models have been advanced across several professions, with the greatest numbers of models being advanced in the management, health professions, and education literatures (Bozeman $\&$ Feeney, 2007). Typically, in these literatures, mentorship models align with one of the two tracks noted above or a combination of elements from the two. Additionally, different levels of importance emerge for the various components of the mentor-protégé relationship (Allen \& Eby, 2004) on the continuum between knowledge and skill development and psychosocial components of mentoring. Allen and Eby (2004) suggest further study to establish the importance of the primary (salary and career outcomes) versus secondary psychosocial outcomes (job satisfaction and career opportunities) across different disciplines in order to establish key characteristics of mentor-protégé relationships.

For the purposes of this study, we adopted the following definition of mentoring initially proposed by Bozeman and Feeney (2007):

... a process for the informal transmission of knowledge, social capital, and psychosocial support perceived by the recipient as relevant to work, career, or professional development; mentoring entails informal communication, usually face-to-face and during a sustained period of time, between a person who is perceived to have greater relevant knowledge, wisdom, or experience (the mentor) and a person who is perceived to have less (the protégé). (p. 731) 
From this perspective, mentorship involves the transfer of knowledge, skills, and social capital related to the workplace from the mentor to the protégé. The GEDI program provided opportunities for the participants to build knowledge about evaluation and culturally responsive evaluation as well as social networking and informal opportunities to develop social capital and networks within the evaluation profession. As such, this project addresses all three expectations of the mentor-protégé relationship in order to address which ones emerge as the most important to early career GEDI alumni.

\section{Mentorship Models}

Mentorship programs may be classified into four general categories of mentor-protégé relationships, including (a) apprenticeship models, (b) training program models, (c) coaching models, and (d) collegial models (Allen \& Eby, 2004; Davis, 2005). These models differ in the prescribed relationship between mentor and protégé, as well as their individual emphases on skill building, networking, or emotional support components of the mentor-protégé relationship. Two of the models, the apprenticeship model and the training program model, are related to the development of the protégés' professional knowledge or skills. In these models, the mentor serves as a guide for the enhancement and development of expected knowledge within the profession often as a direct or ancillary supervisor to the mentee. The coaching model and the collegial model of mentorship are focused on the development of psychosocial components of the profession. Several forms of mentorship opportunities are included and encouraged in the GEDI experience, including formally required mentorship during the course of the program and access to a larger professional network within the American Evaluation Association after graduation from the program.

The first model, the apprenticeship model of mentoring, is often utilized in established and regulated training programs for early career professionals. These apprenticeship models of mentorship are common among early career physicians and attorneys. In these types of programs, early career protégés work alongside a "seasoned" mentor in order to develop their professional skills and networks. A distinguishing factor of these types of programs is that the mentor is often the protégés assigned supervisor and often a gatekeeper into the profession through formal evaluations of the protégé. However, these formalized programs, while guiding the protégé in formal skill and knowledge training, may not adequately support the emotional or social needs of the protégé.

A second model, the training program model, combines semiformal, unregulated mentorship with a structured training program. The training program model involves a formal pairing of a protégé with a mentor who performs the job duties of the protégés profession, but is not responsible for evaluating the protégés job performance (Davis, 2005). In addition, 
the training program model often provides structured interactions for selection and maintenance of the mentor-protégé relationship. Examples of this model of mentorship include adult teacher training programs, or urban school leadership residencies, where protégés are paired with nonsupervising teachers or principals while completing an extended internship in their field. The training program model provides protégés access to additional knowledge and support in their chosen field, while providing the confidentiality needed to garner the emotional and social support of the mentor. The GEDI program provides students with an opportunity to interact with seasoned professionals and scholars, who assist them in developing evaluation protocols and other skill building to benefit their program site.

Another variation of mentoring is seen in coaching models, where program mentors support the protégé through both their program experience and in their subsequent professional career. This model combines formalized training with unstructured opportunities to access experienced practitioners in the field. These programs provide resources for the protégé outside of their typical work environment by promoting access to crossfunctional or cross-institutional relationships with senior leaders in the profession. Such relationships provide protégés with additional perspectives about their knowledge or skill development, as well as their role within profession (Davis, 2005; Kram \& Isabella, 1985). A U.S. Department of Labor Study in 1999 found that the classroom learning followed by coaching mentorship leads to better learning outcomes than traditional classroom learning alone (Benabou \& Benabou, 1999). The GEDI program provides this type of access to evaluation mentors through its requirement of selecting mentors in the field. These mentors inform GEDI participants' evaluation work throughout the program.

Finally, collegial mentorships are informally structured relationships with mentors often initiated by the protégés themselves. Collegial mentorship reflects the earliest forms of workplace mentorship, before mentorship became a component of formalized training programs for professional development. In these relationships, informal workplace relationships provided psychosocial or networking support for the protégé in relationships often described as "friendships" (Davis, 2005).

Typically, training or workplace programs have capitalized on the benefits of these relationships by providing access to a network of supporters and/or alumni who serve as mentors for early career professionals. Protégés seeking these types of mentorship relationships report less interest in technical skill building or knowledge. Instead, the mentors serve as sounding boards, provide emotional support, and promote access to wider collegial networks for the protégé. After graduation, the GEDI program provides this support for its alumni through programming at the AEA Annual Meeting, alumni events, and continued informal interactions with mentors.

Professional mentorship can occur through established professional training programs or education programming. In each model of 
mentorship, the structural formality of the mentor and protégé relationship as well as the nature of the relationship itself plays a central role in its perceived benefits to the protégé (Davis, 2005). While early research on mentorship (Kram \& Isabella, 1985) indicated that mentorship that fulfills the most functions would be most beneficial to protégés, recent research indicates that different types of mentorship may be beneficial for different protégés or at different points within the protégés' careers.

Early career evaluators may possess any combination of expectations from their mentor-protégé relationship. This study will explore expectations of the mentorship relationship and mentors among participants in the GEDI program. Building from the established models of mentorship, this research will inform the mentorship expectations and models that would be most useful to diverse, early career evaluators who participated in the GEDI program.

\section{Method}

The researchers used Q methodology (Brown, 1980; McKeown \& Thomas, 1988; Stephenson, 1953) to investigate GEDI participants' views about mentoring. At its most basic description, in a typical Q study, participants express their opinion by ranking a set of stimuli-statements, pictures, objects, etc. During this process, participants place the items along a continuum, usually from "Most Agree" to "Most Disagree," or a similar configuration that allows them to sort the items in some kind of rank order.

The final rankings (known as the $\mathrm{Q}$ sorts) are then correlated and factor analyzed. This process helps to identify Q sorts that share a similar structure and therefore represent a similar perspective or point of view.

It has been widely used in fields such as political science, nursing, education, and marketing, and recently, sparked the interest of the evaluation community. For instance, the American Evaluation Association has seen an increase in Q methodology-related submissions (e.g., Balutski, Janson, \& Militello, 2013; Brown, Militello, Balutski, \& Janson, 2013; Gomez, 2012; Gomez \& Shartrand, 2011; Shartrand, Gomez, \& Giordan, 2009).

Q method differs from other approaches for investigating people's opinions (surveys, focus groups, interviews) in that individuals assess the importance of statements relative to other statements. This allows them to focus on the issues that are most important to them and, thus, the perspectives that emerge from the data are more likely to be those of the participants of the study than those of a researcher imposing predefined categories on participants.

\section{Procedure}

The procedure for Q methodology research consists of definition of topic and selection of statements, selection of participants, ranking of statements, 
and statistical analysis and interpretation. Each of these steps is explained below.

\section{Definition of Topic and Selection of Statements}

For this study we searched for statements about the purpose of mentoring relationships in higher education literature. We collected an initial bank of 72 statements—called the Q concourse (Brown, 1980; Stephenson, 1953). After revising and rewriting the statements and checking for duplication, we finally settled for a list of 28 statements. In Q methodology, the final list of statements to be sorted by the participants is called the Q sample (Table 4.1).

\section{Selection of Participants}

For this study, participants were recruited with the help of the current administrators of the GEDI program, who provided us with contact information of 59 alumni of the program. Participants were contacted via email. Twelve email addresses had expired and could not be used. In total, 26 individuals responded to the invitation to participate. They had been selected to participate in the GEDI program between 2003 and 2012. The group was comprised of 15 females and 11 males, with experience as evaluators ranging from zero to seven years at the time of participating in the study. Other demographic information including race, ethnicity, current employer, and highest degree achieved at the time of participation in the study is shown in Table 4.2.

\section{Data Collection: Q Sorting}

The study was conducted online using FlashQ, an open-source application for performing Q sort research (Hackert \& Braehler, 2007). Participants were sent a link via email to access the statements. Participants were asked to read through the 28 statements and then to sort them into three piles using the following condition of instruction: "In your opinion, what should be the most important characteristics of a GEDI mentor?" The underlying motive behind this instruction was to motivate participants to think back to their GEDI experience and rank the statements in terms of what they needed or would have preferred as interns. They were not evaluating or ranking their mentorship experience during their participation in the program; we were just trying to gauge their opinion of what characteristics, in their view, make a good mentor.

In one pile participants placed those statements about which they felt positive and in the other pile those statements about which they felt negative. If there were statements toward which the participants felt neutral, they were instructed to place them in a middle neutral pile. This provisional sorting process was then followed by the final Q sort, which began with 


\section{Table 4.1. Q Sample Used in the Study}

In your opinion, what should be the most important characteristics of a GEDI

No. mentor? A mentor ....

$1 \quad$ who meets with me regularly.

2 who listens to me and understands what I want to achieve as an evaluator.

3 who gives me assignments or tasks that prepare me for an evaluation position after graduation/participation in GEDI.

$4 \quad$ who helps me to lay out concrete steps to achieve success in my career as evaluator.

5 who challenges me intellectually.

$6 \quad$ who exposes me to new evaluation ideas and experiences.

$7 \quad$ who gives me assignments that present opportunities to learn new skills.

8 who provides me with positive feedback regarding my performance as evaluator.

9 who encourages me to prepare for advancement in my evaluation career.

10 who discusses my questions or concerns regarding feelings of competence, commitment to advancement, or relationships with colleagues.

11 who encourages me to try new ways of behaving in my role as evaluator.

12 who encourages me to talk openly about anxieties and fears that detract from my work.

13 who helps me to expand my professional networks.

14 who introduces me to influential people in the evaluation field.

15 who has experience mentoring other evaluators.

16 who invites me collaborate in her evaluation projects.

17 who invites me to coauthor journal papers or books.

18 who gives advice without dictating actions.

19 who shares history of his/her career with me.

20 who demonstrates good listening skills in our conversations.

21 who shares personal experiences as an alternative perspective to my

problems.

22 who keeps feelings and doubts I share with him/her in strict confidence.

23 who shares my same attitudes and values regarding evaluation.

$24 \quad$ I would like to be like my mentor when I reach a similar position in my career.

25 who is a recognized individual in the evaluation field.

26 with an active research and publication agenda.

27 who is an active member of professional evaluation societies.

28 with strong technical and analytical skills.

participants looking at the statements in the positive pile and allocating them a place in the right-hand side of the sorting grid (Figure 4.1).

Allocating items to the ranking grid forces participants to sort the statements relative to each other and reveal their actual preferences (Webler, Danielson, \& Tuler, 2009). In some cases, the number of statements in an initial pile exceeds the number of places available in the sorting grid. For example, there can be more statements in the positive pile than spaces in the grid. In this case, participants have to make compromises in what statements they choose to allocate to the available spaces in the sorting grid. 
Table 4.2. Demographics of Participants

\begin{tabular}{|c|c|c|}
\hline Category & Options & $N=26$ \\
\hline \multirow[t]{8}{*}{ Years of evaluation experience } & No evaluation experience & 9 \\
\hline & 1 year & 5 \\
\hline & 2 years & 3 \\
\hline & 3 years & 4 \\
\hline & 4 years & 1 \\
\hline & 5 years & 2 \\
\hline & 6 years & 1 \\
\hline & 7 years & 1 \\
\hline \multirow[t]{6}{*}{ Employer } & Federal Government & 2 \\
\hline & Independent & 1 \\
\hline & NGO & 8 \\
\hline & Other & 3 \\
\hline & State Government & 1 \\
\hline & University & 11 \\
\hline \multirow[t]{5}{*}{ Area of experience } & Elementary/secondary education & 3 \\
\hline & Higher education & 2 \\
\hline & Public Health & 9 \\
\hline & Sciences and Engineering (STEM) & 5 \\
\hline & Other/unspecified & 7 \\
\hline \multirow[t]{4}{*}{ Race } & American Indian or Alaska Native & 4 \\
\hline & Asian & 1 \\
\hline & Black/African American & 16 \\
\hline & Mixed (self-defined) & 5 \\
\hline \multirow{2}{*}{ Ethnicity } & Hispanic & 3 \\
\hline & Non-Hispanic & 23 \\
\hline \multirow[t]{2}{*}{ Gender } & Female & 15 \\
\hline & Male & 11 \\
\hline \multirow[t]{2}{*}{ Highest degree completed } & Master's & 18 \\
\hline & Doctoral & 8 \\
\hline
\end{tabular}

The participants repeated the same process with the negative and the neutral pile. When participants were finished, they had sorted the 28 statements into the shape shown in Figure 4.1. At the end of the sorting procedure, participants had the opportunity to write down and explain why they ranked the statements in the way they did. Their open-ended responses were used in the interpretation of the findings.

\section{Statistical Analysis}

Statistical analyses in Q methodology seek to find patterns across participants' $Q$ sorts. This is done by identifying how alike (or unlike) each participant's Q sort is from that of other participant. To this end, the researcher first looks for intercorrelations among participants' $N$ Q sorts (i.e., persons, not traits, statements, or items are correlated); then these intercorrelations are confirmed by carrying a by-person factor analysis on the $N \times N$ correlation matrix (Hurtienne \& Kaufmann, 2011). The resulting factors are composed 
Figure 4.1. Q-sorting distribution used in the study $(n=28)$.

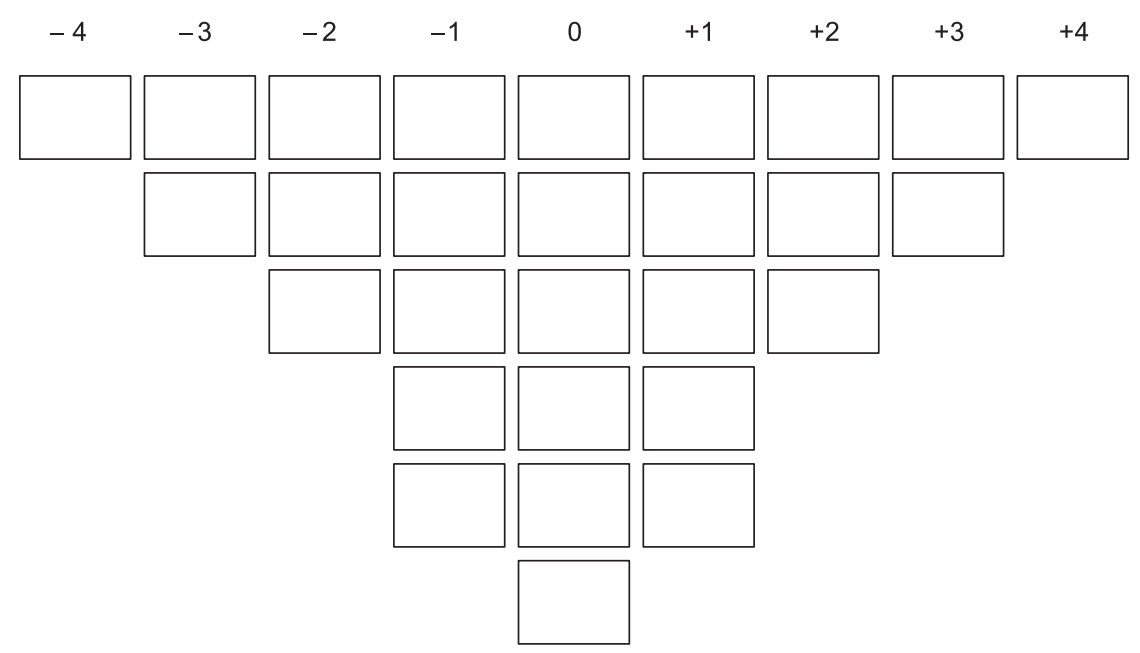

by the participants whose Q sorts have a similar structure, are related to each other, and therefore indicative of a shared perspective or opinion. For this study, the analysis was conducted using PQMethod (Schmolck, 2012), a dedicated computer software for the analysis of $\mathrm{Q}$ sort data. To analyze the data, a correlation matrix was created to compare levels of agreement among the $26 \mathrm{Q}$ sorts followed by a factor analysis on the correlation matrix to group together, as one factor, $\mathrm{Q}$ sorts that had similar rankings.

\section{Results}

Three distinct factors or perspectives were extracted from the analysis. The final three factors accounted for 23 of the 26 completed Q sorts. Three sorts that did not meet the significance criteria in any of the factors were eliminated from the analysis.

\section{Interpretation and Discussion}

For the interpretation of factors, we follow the approach proposed by Watts and Stenner (2012). We created interpretation crib sheets for each one of the factors. We identified, for each factor, the items given the highest ranking, the lowest ranking, and the items ranked higher or lower than by any other study factors. In the section that follows, we present the interpretation of each perspective with its accompanying interpretation crib sheet.

Perspective A: I Want to Be a Professional Evaluator and Need Mentors Who Help Me to Achieve That. This perspective is shared by persons who seem to be considering professional or academic careers in 
Table 4.3. Interpretation Crib Sheet for Factor 1

\begin{tabular}{|c|c|}
\hline No. & Statement and Ranking in Factor Array \\
\hline & Item ranked at +4 \\
\hline \multirow[t]{2}{*}{04} & $\begin{array}{l}\text { A mentor who helps me to lay out concrete steps to achieve success in my career } \\
\text { as evaluator. }+4\end{array}$ \\
\hline & Items ranked higher by factor 1 than by any other factor \\
\hline 03 & $\begin{array}{l}\text { A mentor who gives me assignments or tasks that prepare me for an evaluation } \\
\text { position after graduation/participation in GEDI. }+3\end{array}$ \\
\hline 14 & A mentor who introduces me to influential people in the evaluation. +3 \\
\hline 13 & A mentor who helps me to expand my professional networks. +2 \\
\hline \multirow[t]{2}{*}{17} & $\begin{array}{l}\text { I would like to have a mentor who invites me to coauthor journal papers or } \\
\text { books. }+2\end{array}$ \\
\hline & Items ranked lower by factor 1 than by any other factor \\
\hline 05 & Mentor who challenges me intellectually. +1 \\
\hline 10 & $\begin{array}{l}\text { A mentor who discusses my questions or concerns regarding feelings of } \\
\text { competence, commitment to advancement, or relationships with colleagues. } \\
-1\end{array}$ \\
\hline 20 & A mentor who demonstrates good listening skills in our conversations. -1 \\
\hline 22 & $\begin{array}{l}\text { A mentor who keeps feelings and doubts I share with him/her in strict } \\
\text { confidence. }-1\end{array}$ \\
\hline 11 & $\begin{array}{l}\text { A mentor who encourages me to try new ways of behaving in my role as } \\
\text { evaluator. }-3\end{array}$ \\
\hline & Item ranked -4 \\
\hline 23 & $\begin{array}{l}\text { I would like to work with a mentor who shares my same attitudes and values } \\
\text { regarding evaluation. }-4\end{array}$ \\
\hline
\end{tabular}

evaluation (Table 4.3). Therefore, central to this perspective are mentors who can help them acquire marketable skills through specific tasks or assignments that prepare them for an evaluation position after graduation or participation in the GEDI program $[3,+3] .{ }^{1}$ As one participant stated when explaining their sorting decisions,

More than anything, the process of becoming an evaluator requires apprenticeship in actually conducting evaluations. Conducting evaluations are the assignments/opportunities that would make the GEDI experience transformative; it is experience with a capacity-building purpose. In order for GEDI to truly 'learn by doing,' mentors should consider encouraging the cultivation and integration of new skills in GEDI assignments.

Combined with the importance of gaining practical skills through tasks and assignments is an emphasis on the importance of mentors who invite them to coauthor journal papers or books $[17,+2]$. This might indicate that people who share this perspective are considering careers in higher education.

Participants who share this perspective see networking as a very important element in the path to becoming successful evaluators. This perspective strongly expresses the expectation that mentors help interns connect 
them to influential people in the evaluation community $[14,+3]$ and expand their professional networks $[13,+2]$. As one of the participants who loaded into this factor expressed:

Networking is highly important if an individual seeks to broaden their perspective and scope in the field of evaluation. Social networks are also highly influential to the success of individual if they present you with access to other systems and stakeholders.

On the other side of the spectrum, for participants who loaded into this factor, mentors and protégés sharing the same values and attitudes about evaluation is the least important aspect of a mentoring relationship $[23,-4]$. Furthermore, the development of a personal connection with the mentor is not central to the goals of a mentoring relationship $[20,-1 ; 22$, $-1]$. As one of the participants commented:

[...] as long as there is a space of mutual professional respect between mentor and protégé, I don't think personal issues are warranted or appropriate topics of conversation. That stated, I feel that all mentors have the professional know-how to engage with protégés in personal dialogue without coming across as dismissive or uninterested.

Or as other participant expressed,

This is least important because it is something you can get from your academic advisor or any other friend or professional and not as important in the grand scope of what I really would like to get from a GEDI mentor.

Perspective B: I Would Like to Have a Mentor Who Can Show Me How to Wear the Evaluation Hat When the Opportunity Arises. This perspective places primary emphasis on the development of new skills. Individuals who share this opinion prefer mentors who provide them with opportunities to learn new skills (Table 4.4).

$(7,+4)$. What they seek in a mentor is someone with strong technical and analytical skills $(28,+3)$, who challenges them intellectually $(5,+3)$, who provides them with positive feedback regarding their performance as evaluators $(8,+2)$, and who meets with them regularly $(1,+2)$.

They do not expect that a mentor helps them to achieve success in career as professional evaluators $(17,0)$. In fact, for this perspective, publishing and expanding their professional networks are not important characteristics that define mentoring relationships $(17,-3)$. Therefore, this is likely to be the perspective of individuals who are not necessarily interested in pursuing academic or full-time professional careers in evaluation. Rather, they seem to be more interested in being able to use or apply their evaluation skills in their workplace or when the opportunity arises. This perspective 
Table 4.4. Interpretation Crib Sheet for Factor 2

\begin{tabular}{|c|c|}
\hline No. & Statement and Ranking in Factor Array \\
\hline & Item ranked at +4 \\
\hline \multirow[t]{2}{*}{07} & $\begin{array}{l}\text { A mentor who gives me assignments that present opportunities to learn new } \\
\text { skills. }+4\end{array}$ \\
\hline & Items ranked higher by factor 1 than by any other factor \\
\hline 05 & Mentor who challenges me intellectually. +3 \\
\hline 28 & A mentor with strong technical and analytical skills. +3 \\
\hline 01 & A mentor/mentor who meets with me regularly. +2 \\
\hline \multirow[t]{2}{*}{08} & $\begin{array}{l}\text { A mentor who provides me with positive feedback regarding my performance } \\
\text { as evaluator. }+2\end{array}$ \\
\hline & Items ranked lower by factor 1 than by any other factor \\
\hline 13 & A mentor who helps me to expand my professional networks. -1 \\
\hline 16 & A mentor who invites me to collaborate in her evaluation projects. -1 \\
\hline 21 & $\begin{array}{l}\text { A mentor who shares personal experiences as an alternative perspective to } \\
\text { my problems. }-3\end{array}$ \\
\hline 17 & $\begin{array}{l}\text { I would like to have a mentor who invites me to coauthor journal papers or } \\
\text { books. }-3\end{array}$ \\
\hline 26 & A mentor with an active research and publication agenda. -3 \\
\hline & Item ranked -4 \\
\hline 25 & $\begin{array}{l}\text { I would like to have a mentor who is a recognized individual in the } \\
\text { evaluation field. }-4\end{array}$ \\
\hline
\end{tabular}

is summarized by a participant reflecting about the role of mentoring in the GEDI program:

[GEDI] mentoring experience should prepare me to think about the different hats I could wear as an evaluator and to develop those that fit me best-and to see where the opportunities were! Also, it helps when you're feeling like a ship at sea applying for jobs.

\section{Perspective C: I Need a Mentor Who Is a Good Listener and I Can} Reach Out to for Advice. For this perspective, the most important characteristic of a mentor is their capacity to listen actively $[2,+4 ; 20,+3]$ and give advice $[18,+1]$ when needed (Table 4.5 ).

They do not expect a mentor to have strong technical and analytical skills $(28,-1)$, or who is a member of professional evaluation societies $(27,-3)$, but someone to whom they can go to when they have questions or doubts. Different from the previous perspectives, they do not think it is important to have a mentor who gives them assignments or feedback on their performance as evaluator $(8,-2)$. As stated by one of the participants whose Q sort loaded significantly on this factor, "I am not looking for more work to do, but refinement and assistance with what is already on my plate and situation myself for the future that I envision." This perspective seems to be aligned with the collegial mentorship approach (Davis, 
Table 4.5. Interpretation Crib Sheet for Factor 3

\begin{tabular}{|c|c|}
\hline No. & Statement and Ranking in Factor Array \\
\hline & Item ranked at +4 \\
\hline \multirow[t]{2}{*}{02} & $\begin{array}{l}\text { Mentor who listens to me and understands what I want to achieve as an } \\
\text { evaluator. }+4\end{array}$ \\
\hline & Items ranked higher by factor 1 than by any other factor \\
\hline 20 & A mentor who demonstrates good listening skills in our conversations. +3 \\
\hline 22 & $\begin{array}{l}\text { A mentor who keeps feelings and doubts I share with him/her in strict } \\
\text { confidence. }+2\end{array}$ \\
\hline 18 & A mentor who gives advice without dictating actions. +1 \\
\hline \multirow[t]{2}{*}{19} & A mentor who shares history of his/her career with me. +1 \\
\hline & Items ranked lower by factor 1 than by any other factor \\
\hline 6 & A mentor who exposes me to new evaluation ideas and experiences. +1 \\
\hline 7 & $\begin{array}{l}\text { A mentor who gives me assignments that present opportunities to learn new } \\
\text { skills. }+1\end{array}$ \\
\hline 3 & $\begin{array}{l}\text { A mentor who gives me assignments or tasks that prepare me for an evaluation } \\
\text { position after graduation/participation in GEDI. } 0\end{array}$ \\
\hline \multirow[t]{2}{*}{28} & A mentor with strong technical and analytical skills. -1 \\
\hline & Item ranked -4 \\
\hline 23 & $\begin{array}{l}\text { I would like to work with a mentor who shares my same attitudes and values } \\
\text { regarding evaluation. }-4\end{array}$ \\
\hline
\end{tabular}

2005), in which protégés give priority to mentors who serve as sounding boards, provide emotional support, and help them to access wider collegial networks.

Interestingly, participants who loaded into this factor are those who reported longer evaluation experience. Thus, it is likely that this perspective on mentoring stems from their experience as evaluators. The median experience time as evaluators in this group was 6 years, ranging from 3 to 6 years. This might explain that they see mentors not as teachers who can teach them new skills, but as confidants who they can trust with questions, feelings, and doubts $(22,+2)$. Technical skills, as one participant observed, "can be acquired from training or independent study."

Similar to Factor A, Factor C also rejects the idea that mentors and mentees should share the same attitudes and values regarding evaluation $[23,-4]$. In fact, one of the participants sees this as detrimental for the professional development of evaluators:

Working with a mentor who shares your values and attitudes with regard to evaluation is not always good because then a mentee does not acquire an alternative viewpoint. I've been mentored from professionals who I haven't agreed with and our differing perspectives actually enriched the relationship and the mentoring experience. 


\section{Conclusion}

This study set out to investigate perspectives about mentoring among former participants of the GEDI program. Specifically, we wanted to know what characteristics they considered more important in a mentoring relationship. We asked participants to think retrospectively and give their opinion on the most important characteristics a GEDI mentor should have based on what they would have liked or needed when they participated in the GEDI program.

The results of this study highlight the characteristics of mentoring relationship desired by early career evaluators. Whether mentoring relationships have been established through formal or informal aspects of the GEDI program, early career GEDI clearly desire specific outcomes from these relationships, based on their professional aspirations and tenure in the field. Three distinct perspectives about mentoring emerged from the analysis.

The first perspective (I want to be a professional evaluator and need mentors who help me to achieve that) is held by a group of evaluators who are likely considering professional or academic careers in evaluation. What they seek in a mentor is somebody who helps them to develop technical skills, expands their professional networks, and invites them to collaborate in their research and writing projects. In this group, participants seek to develop the skills, connections, and professional profile that make them marketable in the professional or academic evaluation sector.

A second perspective (I would like to have a mentor who can show me how to wear the evaluation hat when the opportunity arises) emerges from a group of individuals who are not necessarily interested in pursuing professional or academic careers in evaluation. They seem to be primarily interested in developing a set of skills that allows them to be informed users of evaluation when the opportunity arises. Therefore, for them, the most beneficial mentoring relationship is one which involves a mentor with strong technical and analytical skills, who challenges them intellectually, and who provides relevant feedback regarding their performance as evaluators. Different from the first perspective above, for participants who share this perspective, coauthoring journals or books, or collaborating with mentors in evaluation projects are not the most important outcomes of mentorship.

The third perspective (I need a mentor who is a good listener and I can reach out to for advice) emerged from a group of participants who came into the GEDI program with a fair amount of knowledge and experience. They are confident they have, or can develop, the skills they need to be successful evaluators. Therefore, what they seek in the program is an advisor, a person they can reach out to for advice or for answers to their questions. For this perspective, skill-based training was less important than the ability to "confirm doubts" and "gain clarity" about their existing projects.

As training program for evaluation, the GEDI program provides many opportunities for participants and alumni to connect with potential 
mentors. GEDI participants and interns obtain access to mentors through many different types of mentor-protégé relationship models. The findings from this study show that mentoring is not unidimensional; that perceptions and expectations of mentoring are defined to a great extent by the professional needs, background, and expectation of the participants. Our results reinforce the continued, and even expanded, use of both the formal and informal mentorship relationships. On the one hand, very early career GEDI participants expect formal introduction to professional expectations. However, a few years into their careers as evaluators, GEDI members desire more informal and equal relationships with informal mentors. Thus, the formal aspects of mentoring should not be considered a substitute for informal mentoring relationships but should be offered as a complement or an addition to informal mentoring.

In addition, the selection of informal mentors through the development of the career seems particularly important for GEDI participants. Thus, the fact that the GEDI program involves the mentor and protége in the formation of the mentoring partnership seems to be particularly relevant. When mentors and protégés perceive they have a voice in the matching process, they may invest more in the relationship.

This is an exploratory study and the findings cannot be generalized. That is not the intended use of Q methodology. There is still much to be understood about mentorship and the early career evaluator. However, mentoring is an important professional development tool that can be used to enlarge the extent and impact of the GEDI program.

One of the recommendations that we make based on our findings is that the GEDI program identifies career plans and aspirations of participants during the selection process and uses those as criteria for selecting mentors. Much can be learned and gained by associating with people who have the skills, expertise, and willingness to help early career evaluators achieve their individual professional goals. It is not unreasonable to assume that mentoring relationships in which mentors and protégés share similar perspectives about mentoring and career paths are likely to be more productive, meaningful, and relevant for the protégé. This study also opens up more avenues for investigation. Further research on this issue can include surveying the current mentors and protégés for their information about how mentoring impacted their career plans. Also, since the GEDI program requires the selection of formal and informal mentors, comparative studies with nonmentored early career evaluators may provide additional insights into the impact and effectiveness of mentoring programs.

Since the early 1970s, many books and articles have been written about mentoring across several disciplines and fields. However, much remains to be uncovered about the mentorship of evaluators. We began this research with the idea that we each had different requirements and expectations from the mentorship relationship. As the GEDI program matures and alumni become further established in their careers, the requirements will almost 
certainly advance. Pursuing research about mentorship outcomes and other mentorship needs should enhance theoretical and practical understandings of mentorship needs and results for evaluators throughout their career cycle.

\section{Note}

1. The first number corresponds to the statement in the merged Q sort and the second one to its ranking.

\section{References}

Allen, T. D., \& Eby, L. T. (2004). Factors related to mentor reports of mentoring functions provided: Gender and relational characteristics. Sex Role, 50(1-2), 129-139.

Balutski, B., Janson, C., \& Militello, M. (2013, October). What 2 can do for you. Paper presented at the annual meeting of the American Evaluation Association, Washington, DC.

Benabou, C., \& Benabou, R. (1999). Establishing a formal mentoring program for organizational success. National Productivity Review, 18(2), 1-8.

Bozeman, B., \& Feeney, M. K. (2007). Toward a useful theory of mentoring: A conceptual analysis and critique. Administration \& Society, 39(6), 719-739.

Brown, S. (1980). Political subjectivity: Applications of $Q$ method in political science. New Haven, CT: Yale University Press.

Brown, S., Militello, M., Balutski, N., \& Janson, C. (2013, October). 2 methodology: A participatory evaluation approach that quantifies subjectivity. Workshop held at the annual meeting of the American Evaluation Association, Washington, DC. Retrieved from http://www.eval.org/e/in/eid $=1 \& s=66 \&$ print $=1 \&$ req $=$ info

Chao, G. T., Walz, P. M., \& Gardner, P. D. (1992). Formal and informal mentorship: A comparison on mentoring functions and contrast with nonmentored counterparts. Personnel Psychology, 45, 619-636.

Dalton, G. W., Thompson, P. H., \& Price, R. L. (1977). The four stages of professional careers-A new look at performance by professionals. Organizational Dynamics, 6(1), $19-42$.

Davis, A. L. (2005). An investigation of formal mentoring relationships and programs: A meta-analysis (Doctoral dissertation). City University of New York, New York.

Gomez, R. (2012, October). Opinions count... so get them right: Using Q methodology to inform program evaluation and planning. Paper presented at the annual meeting of the American Evaluation Association, Minneapolis, MN.

Gomez, R., \& Shartrand, A. (2011, November). Beyond 'agree' and 'somewhat disagree': Using $Q$ methodology to reveal values and opinions of evaluation participants. Paper presented at the annual meeting of the American Evaluation Association, Anaheim, CA.

Hackert, C., \& Braehler, G. (2007). FlashQ (Version 1) [Computer software]. Retrieved from http://www.hackert.biz/flashq/downloads/

Hurtienne, T., \& Kaufmann, G. (2011). Methodological biases. Inglehart's world value survey and Q methodology. Journal of Human Subjectivity, 9(2), 41-69.

Kanter, R. M. (1977). Men and women of the corporation. New York, NY: Basic Books.

Kram, K. (1985). Mentoring at work: Developmental relationships in organizational life. Lanham, MD: University Press of America.

Kram, K., \& Isabella, L. A. (1985). Mentoring alternatives: The role of peer relationships in career development. Academy of Management Journal, 28(1), 110-132.

Levinson, D. J., Darrow, C. N., Klein, E. B., Levinson, M. H., \& McKee, B. (1978). The seasons of a man's life. New York, NY: Alfred A. Knopf. 
McKeown, B., \& Thomas, D. (1988). Q methodology. New York, NY: Sage.

Scandura, T. A. (1992). Mentorship and career mobility: An empirical investigation. Journal of Organizational Behavior, 13, 169-174.

Schmolck, P. (2012). PQMethod [Computer Software], Version 2.1.3. Retrieved from http://schmolck.userweb.mwn.de/qmethod/

Shapiro, E. C., Haseltine, F. P., \& Rowe, M. P. (1978). Moving up: Role models, mentors and the patron system. Sloan Management Review, 19(3), 51-58.

Shartrand, A., Gomez, R., \& Giordan, J. (2009, November). The chemistry of innovation: An exploratory assessment of attitudes toward innovation among academic chemists. Poster presented at the annual meeting of the American Evaluation Association, Orlando, FL.

Stephenson, W. (1953). The study of behaviour: Q technique and its methodology. Chicago, IL: University of Chicago Press.

Watts, S., \& Stenner, P. (2012). Doing Q methodological research: Theory, method and interpretation. London, UK: Sage.

Webler, T., Danielson, S., \& Tuler, S. (2009). Using Q method to reveal social perspectives in environmental research. Greenfield, MA: Social and Environmental Research Institute.

Whitely, W., Dougherty, T. W., \& Dreher, G. F. (1992). Correlates of career-oriented mentoring for early career managers and professionals. Journal of Organizational Behavior, 13, 141-154.

RICARDO L. GÓMEZ is an assistant professor of quantitative research and evaluation methods in the College of Education at Universidad de Antioquia, Medellin, Colombia.

ASMA ALI has an MA in sociology and is currently ABD in urban planning and policy, with a concentration in Community/Economic Development at the University of Illinois at Chicago College of Urban Planning and Policy.

WANDA CASILLAS is currently a research fellow with the University of Michigan Rackham Graduate School and program evaluation consultant with a PhD from the Department of Human Development at Cornell University. 